\title{
THE IMPACT OF COMPUTERS ON CHESS-PROBLEM COMPOSITION
}

\author{
H. le Grand \\ University of Agriculture \\ Wageningen, The Netherlands
}

Currently entries for the third 'World Chess Composition Tournament' are available. They have been published with the suppression of the authors' name and nationality. Now is the time to challenge the problems on their correctness, originality and adherence to the themes. The FIDE permanent committee for chess problems this year supervises 28 participating countries' entries. Classification is in ten sections: two each for two- and threemovers, one each for more-movers, studies and helpmates, selfmates, Circe problems and problems with heterodox pieces. Each country may participate in up to eight sections with a team set for each section.

The number of correct entries has grown remarkably. Computers must have something to do with this, since the sections for which computer checking programs are available score particularly highly on correctness. One also may assume that many countries possess computer programs for testing a subrange on more-movers, for selfmates and Circes.

This is a far cry from the past. One recalls the bad old days of some ten years ago when the Netherlands played Greece on the helpmate pitch. Technically the entries seemed to be well-matched. Yet the Dutch, having computer-tested their helpmates were fully correct whereas they could prove that over fifty percent of the Greek problems were cooked, which is to say admitted several solutions. Clearly the Dutch won the day but their victory was unsatisfactory in that it revealed nothing about the composers' strength.

Since in the WCCT 3 all strong competitors can be assumed to have computers to help them with their checking, results are likely to be a fairer reflection of participants' strength, assuring that only correct problems compete. It follows that the decision in WCCT 3 lies with those sections not readily testable by computers, such as the studies. Originality will be decisive and, of course, the judges' verdict will be final.

So the question arises: Can computers have an impact on originality and on the judgement process?

The rules state that problems previously published in (nearly) the same setting are to be disqualified. It therefore becomes important to search for earlier versions, if any, to the problems submitted. Such a search presumes the existence of problem collections. Though many composers possess some collections, these are most laborious to maintain and update. Unless narrowed to theme or country, a collection of twomovers, e.g., must have over ten thousand items to have some authority. Beyond twomovers, collections are often non-existent. Such that exist have a single search entry only, mostly the theme, so that gathering one composer's output requires searching the entire set.

We conclude that a solution could lie in a computerised problem database, with searching possible by theme, author, source and date of publication and, of course, type of problem. Construction of such a database is a huge task. Even keying the problem data is a staggering labour. Assuming the computer can solve it, there is no need for also inputting the solution, but unfortunately the computer cannot solve them all. Not only that, determining the theme(s) by computer seems beyond human programming capabilities. Ideally, many parties from many countries should co-operate in its creation, if only to make the match independent of the material available locally in various places.

The next question is: can one render the judgement independent of the judges' personal preferences? Many years ago, Vaux Wilson (U.S.A.) proposed to do just that. He awarded points by effects, say 10 for each interference, 12 for pinning and 15 for a minor promotion. His simplistic "MO system" was universally rejected. Also it is probably impossible to describe, let alone quantify all effects. A remote mate is more attractive, e.g., than a mating sequence with the mater close to the King. A few-piece mate in the centre outshines a many-piece, edge-limited one. Here also, taste enters: how many points for a pinned mate when beauty is in the eyes of the beholder? 
Even granted an agreed-upon rating system for set problems, the construction of a computer program to effect it is a major, labour-intensive scientific project, well beyond the hobbyist world in which problem setters dwell. This may be for the best. It is not up to computers to decide all.

We have identified three potential uses of computers in chess-problem contexts: testing correctness, evaluating originality, and aesthetic judgement. In the first field, computers are well-tried and trusted. In the second, databases may impact the field: the search for originality can never be too thorough. That computers will take over the judgement function is unlikely. Even if constructed, a judgement computer program can never do more than assist the judge not replace him.

Photo by The Editor

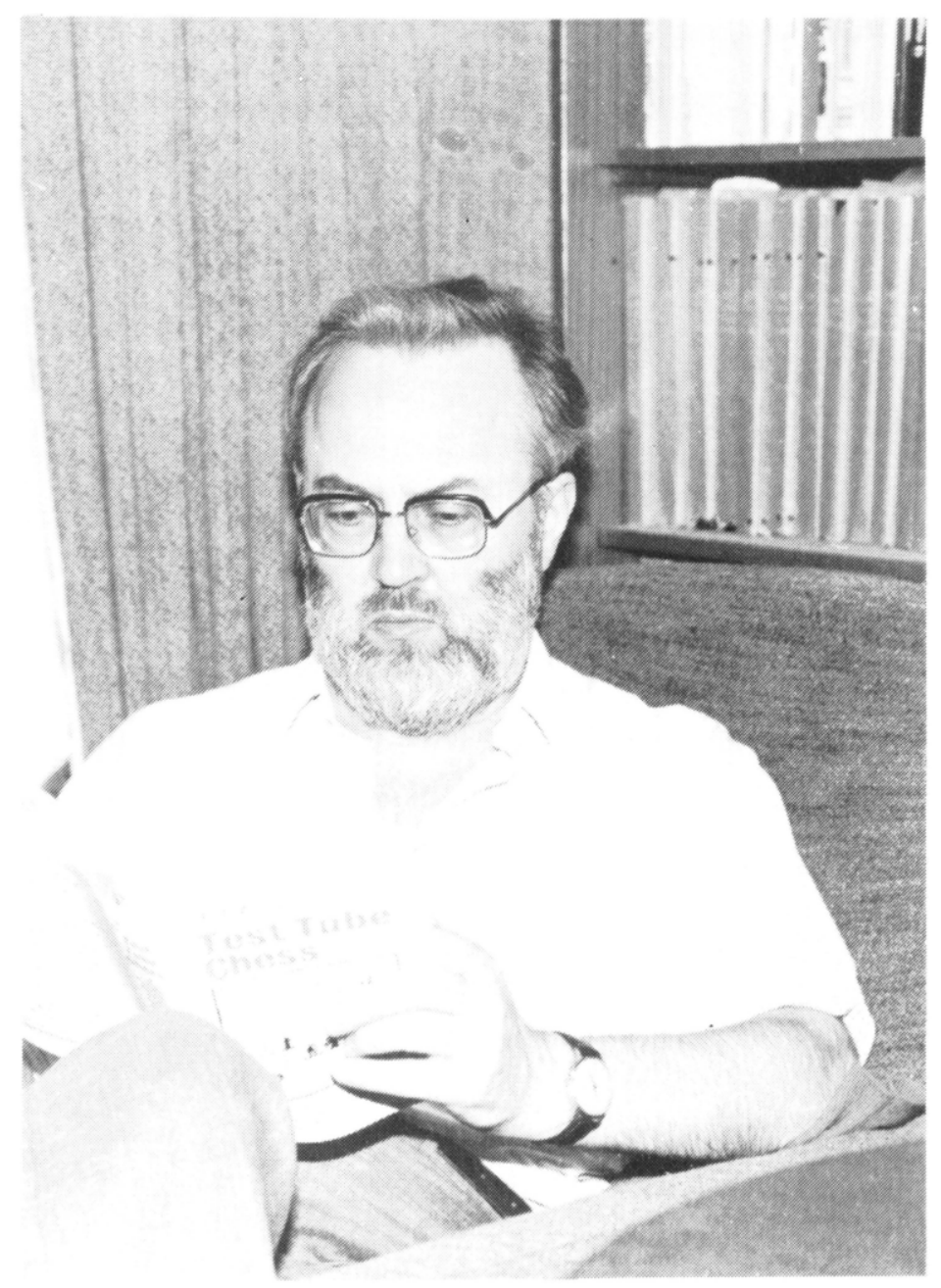

ROYCROFT RUMINATING

Test tube's author planning more beauteous babies? 